\title{
Urinary Tract Infection and Their Risk Factors Association in Renal Transplant Recipients.
}

\author{
Rehana Razzak Khan ${ }^{1}$, Chandan Kumar Roy², A.S.M Nowroz ${ }^{3}$, Ismet Nigar ${ }^{4}$, Ahmed Abu Saleh ${ }^{5}$, \\ ${ }^{1}$ Medical Officer, Department of Microbiology and Immunology, ${ }^{2}$ Assistant Professor, Department of Microbiology and Immunology, ${ }^{3}$ Consultant , \\ Department of Clinical Pathology, ${ }^{4}$ Medical Officer, Department of Microbiology and Immunology, ${ }^{5}$ Professor, Department of Microbiology and \\ Immunology, BSMMU,Dhaka.
}

\begin{abstract}
:
Background: Urinary tract infection (UTI) remains one of the most common and major complications after renal transplantation. Objective: The study was undertaken to get an insight regarding the bacterial pathogen which is responsible for UTI in post renal transplant patients and their risk factors association. Methods: This was an observational study, conducted in the Department of Microbiology and Immunology Bangabandhu Sheikh Mujib Medical University (BSMMU) from December 2010 to December 2011. Twenty- one renal transplant recipients were evaluated for UTI after surgery up to six weeks. Microscopic examination and culture of urine were performed in every pretransplant period, 3rd POD, 7th POD, within six weeks and as per patient's clinical condition. UTI was considered when bacterial count was $\geq$ 103 per $\mathrm{ml}$ of urine along with pus cell count of $>5$ / HPF. Analysis was done by using SPSS ver. 20.0.The level of significance was taken as 0.05 . Student's t test and chi square test were done to compare the variables in UTI and non UTI patients. Result: Total 69 urine specimens were taken from 21 post renal transplant recipients in different periods. Thirteen $(61.90 \%)$ patients developed UTI during the initial post transplant period. Among the 69 urine specimens, 22 (31.88\%) yielded positive results for culture in which Enterococcus spp. (50\%) was the major pathogen isolated. Prolonged urinary catheterization, post operation hospital stay and duration of dialysis were statistically significant risk factors leading to UTI in post renal transplant recipients. Conclusion: Enterococcus spp. is an emerging pathogen responsible for UTI. Prolonged period of catheterization, post operation hospital stay and duration of dialysis are the risk factors for UTI in post renal transplant recipients.
\end{abstract}

Key words: Urinary tract infection, risk factors, Foley's catheter, Enterococcus spp.

[BSMMU J 2014 ; 7 (2) : 129-133]

\section{Introduction:}

Urinary tract infections (UTI) are the most common infectious complications in patients receiving renal transplant for end stage kidney disease ${ }^{1}$. UTI is associated with the development of impaired allograft function, allograft loss, and death ${ }^{2}$. Urinary tract infection compromises approximately 45 to 47 percent of infectious complications of renal transplantation ${ }^{3}$.

In several studies the incidence of UTI has been reported to vary from $31.3 \%$ to $79 \%$ among renal transplant recipi-

Address for Correspondence: Rehana Razzak Khan, Medical Officer Department of Microbiology and Immunology, 572, South Goran, Khilgaon Dhaka, Telephone: 01711222100,E-mail: november_rona@yahoo.com ents $4,5,6,7,2$. A study conducted in Bangabandhu Sheikh Mujib Medical University (BSMMU) in 2003, reported $42(79 \%)$ episodes of UTI within 53 infectious episodes among 31 post renal transplant patients ${ }^{7}$. Besides viral infection, bacterial infection have high incidence of morbidity and mortality. Escherichia coli has been reported as the main uropathogen causing UTI among transplant patient's in studies in Karachi, BSMMU Dhaka and Mexico ${ }^{5,7,4}$.

Other pathogens isolated in Mexico were Candida albicans (21.0\%) and Enterococcus spp. (10.5\%) followed by Pseudomonas aeruginosa, Klebsiella pneumoniae, Morganella morganii, Enterobacter cloacae and Micro- 
coccus spp ${ }^{4}$. Whereas other isolated pathogen in Karachi, were Pseudomonas 12 (18\%) Klebsiella spp. 09(14\%), Morganella morganii $05(08 \%)$, Enterobacter spp. 03 (05\%), Enterococcus spp. $02(03 \%)$ \& MRSA 01(01\%) In BSMMU, Dhaka were Pseudomonas 06 (09\%), Klebsiella $05(08 \%)$, Staphylococcus $03(4.5 \%)$ and Enterococcus $01(1.5 \%)^{7}$.

Risk factors of UTI include pretransplant UTI, prolonged period of hemodialysis before hospitalization, polycystic kidney disease, diabetes mellitus, postoperative bladder catheterization, immunosuppression, allograft trauma, and technical complications associated

with urethral anastomosis ${ }^{8}$. Other risk factors include socio economic status and unhygienic condition, tropical climate, late presentation, lack of knowledge about the spectrum of organism in those areas, diagnostic technique and anti microbial agent ${ }^{9}$.

Iqbal et $\mathrm{al}^{5}$ reported about the risk factors, of UTI in post transplant patients including prolonged period of catheterization, prolonged hospital stay, prolonged period of hemodialysis, stent placement was not found to be a significant risk factor ${ }^{5,10}$

It is advisable to carry out urinary culture on kidney transplant patients within first few months, because of their extreme vulnerability to UTI. Furthermore, urinary culture gives the opportunity of performing an antibiogram, which can lead to appropriate medical treatment ${ }^{6}$. The incidence of UTI following transplantation has decreased because of improvements in surgical procedure, rapid removal of the urethral catheter, refinement of immunosuppressive therapy, and routine administration of antibiotic therapy ${ }^{11}$.

So early detection of UTI and its risk factors in post renal transplant patients is needed for the management and treatment of post renal complication. Therefore for designing a control program of post renal transplant infection the present study was carried out to identify the etiologic agents and risk factors of UTI in post renal transplant patients in BSMMU that will help to increase the chance of graft survival.

\section{Methods:}

This was an observational study carried out in the Department of Microbiology and Immunology, BSMMU, Shahbagh, Dhaka, Bangladesh from December 2010 to December 2011.Institutional review board (IRB) was approved the study to conduct (No.BSMMU/2011/5465, Date: 21-05-2011). Informed written consent was taken from the patients. A total 21 post renal transplant patients from the Department of Nephrology, BSMMU were evaluated for urinary tract infection and their risk factors association. Among the enrolled patients 17 were male \& 3 were female. A Foley catheter was introduced before surgery \& it remains from 5- 10 days afterwards. Urine specimens were taken from each patient in preoperative period for screening \& directly from the catheter on 3rd, 7 th post operative day \& within six weeks.

Urinary studies: At first the catheter collection port was disinfected with $70 \%$ alcohol, and then catheter was clamped below the port and allows the urine to collect in tube for 10- 20 minutes. After that with the help of sterile syringe $5-10 \mathrm{ml}$ of urine was collected in a sterile leak proof container and then transported to the Department of Microbiology and Immunology BSMMU. Microscopic urinary sediment examinations were done after centrifugation of the sample at $1000 \mathrm{~g}$ for 15 minutes on a clinical centrifuge 4 . Urinary quantitative culture was done on Chromo agar media and incubated at $370 \mathrm{c}$ for 24 hours. It was considered a positive result for urinary tract infection (UTI) when bacterial counts were recorded up to 103 or more per $\mathrm{ml}$ of urine and a WBC count of $>5$ / HPF12. Isolated Gram negative and Gram positive organisms were identified by standard phenotypic detection methods. Data regarding duration of dialysis, number of days of Foley's catheter was retained and post operative hospital stay was entered in Statistical Package for Social Sciences Version 20.0. Student's t test and chi square test 
were performed to analyze the data. A Significant $\mathrm{p}$ value was considered less than 0.05 .

\section{Results:}

A total 21 post renal transplant patients were evaluated for development of UTI. Among them 13 (61.90\%) patients developed UTI. A total of 69 urine specimens were collected from these patients of which $22(31 \%)$ yielded culture positive. Enterococci spp. was most common pathogenic organism $(11 ; 50 \%)$ isolated followed by Escherichia coli 04(18.18\%), Enterobacter spp. 02(9.09\%) \& klebsiella spp. 02(9.09\%), Acinetobacter spp., 01(4.54\%) Pseudomonas spp. 01(4.54\%) \& Staph. epidermidis were $01(4.54 \%$ ) (Table-I). ).

\section{Table-I}

Organisms causing urinary tract infection in renal transplant recipients $(n=22)$

\begin{tabular}{ll}
\hline Microorganism & $\mathrm{N}(\%)$ \\
\hline
\end{tabular}

Enterococci. spp.

Escherichia coli

Enterobacter spp.

Klebsiella spp.

Acinetobacter spp

Pseudomonas spp.

Staph. epidermidis

Among the 21 renal transplant recipients $01(4.54 \%)$ patients developed UTI in 3rd POD and 5th POD, $08(38.09 \%)$ patients in 7 th POD \& $09(42.85 \%)$ patients within 6th weeks after transplantation (Fig-1).
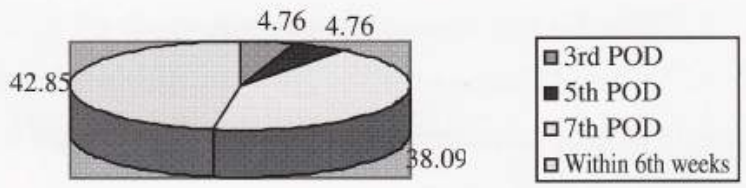

Fig-1: Number of urine culture positive patients in post transplant periods (3rd, 5th,7th POD and within 6th weeks) $n=13$
On 7 days and onwards of catheterization UTI was found in $11(84.61 \%)$. Less than 7 days catheterization UTI developed in $2(15.38 \%)$ patients $(\mathrm{p}=<.001)$ (Table-II).

\section{Table-II}

Duration of catheter associated with UTI in post renal transplant patients $(n=13)$.

\begin{tabular}{llll}
\hline $\begin{array}{l}\text { Duration } \\
\text { of catheter }\end{array}$ & UTI patients & $\mathrm{n}(\%)$ & $\mathrm{p}$ - value * \\
\hline$<7$ days & 2 & $(15.38)$ & \\
$\geq 7$ days & 11 & $(84.61)$ & \\
\hline
\end{tabular}

* Chi square test was done to measure the level of significance.

Among UTI patients mean duration of dialysis $(\mathrm{p}=0.003)$, delay in removal of Foley's catheter $(p=0.002)$ and post transplant hospital stay $(\mathrm{p}=0.001)$ were found statistically significant risk factors for leading to UTI in renal transplant patients of BSMMU (Table-III).

\section{Table -III}

Comparison of characteristics of risk factors of urinary tract infection and non urinary tract infection groups in post transplant patients $(n=21)$

\begin{tabular}{lll}
\hline Parameters & UTI $(\mathrm{n}=13)$ & $\begin{array}{l}\text { Non-UTI P value } \\
(\mathrm{n}=08)\end{array}$ \\
\end{tabular}

Duration of $2-24$ $1-2$ 0.003

Dialysis (months)

Mean duration $7 \pm 2$

$5 \pm 2$ 0.002 of Foleys catheter (days) Post-op. $15 \pm 10$ $10 \pm 5$ 0.001 hospitalization (days) 


\section{Discussion:}

UTI developed in most of the patients $(61.90 \%)$ within $6^{\text {th }}$ weeks of renal transplantation which was seen in present study. This finding was in consistent with the findings of the study by Islam $^{7}$ in BSMMU. He has studied 31 patients, over a period of 2 years and found $79 \%$ UTI in these patient ${ }^{7}$. Iqbal et $\mathrm{al}^{5}$ in 2010 reported UTI in $77 \%$ patients out of 66 renal transplant recipients within 8 weeks of post renal transplant period. Findings of these studies were similar to our observation. UTI in post renal transplant patients are probably due to use of immunosuppressive drugs, urinary catheterization and increased post transplant hospital stay.

In the present study, major pathogen responsible for UTI was Enterococcus spp. (50\%). These observations are also correlate with the data of the study by Mathe et allo who reported Enterococcus spp. as the leading uropathogen causing UTI after renal transplantation. Schieszer et $\mathrm{all}^{3}$ reported in 2008 that, Gram positive organism accounts about $40 \%$ of uropathogen for renal transplant population. Among the gram positive organisms, the predominant pathogen in their studies appear to be Enterococcus spp. Sanchez et $\mathrm{al}^{4}$ in their study found Enterococcus spp (47\%) to be the major bacterial pathogen of UTI in post renal transplant and they have reported Enterococcus spp. as an emerging bacterium responsible for symptomatic infections in kidney transplant patients. In this study, other pathogen besides Enterococcus spp. were Escherichia coli (18.18\%) Enterobacter spp. (9.09\%) Klebsiella spp. (9.09\%), Acinetobacter spp.(4.50\%) Pseudomonas spp.(4.50\%) and Staph epidermidis $(4.50 \%)$. Islam ${ }^{7}$ in his study observed Escherichia coli $(88 \%)$ to be the major bacterial pathogen responsible for UTI followed by Klebsiella spp (6\%),

Pseudomonas spp (3\%) Enterococcus spp (3\%) in post renal transplant patients. This indicates the changing pattern of etiological agents in post renal transplant patients in BSMMU.
Another study in Pakistan by Iqbal et al5 found E. coli $(51 \%)$ to be the predominant organism in UTI followed by Pseudomonas aeruginosa, Klebsiella spp. Morganella morgani, Enterobacter spp., Enterococcus. spp . MRSA. Chuang et $\mathrm{al}^{14}$ in 2005 in US transplant centre reported E. coli (29\%), followed by Enterococcus spp (24\%), Staphylococcus (12\%) and Klebsiella spp.(10\%). Variation in etiological agents of UTI in post renal transplant patient may have geographical variation.

This study showed that, out of 13 UTI patients, 10 patients developed UTI within $7^{\text {th }}$ POD and 9 patients developed UTI between 10th POD till 6 weeks after renal transplantation. Oliveira et $\mathrm{el}^{15}$ in 2001 reported highest number of UTI on $4^{\text {th }}$ POD. But we could not compare our results with the study done by Oliveira et al as catheters was removed from these patients after $4^{\text {th }} \mathrm{POD}^{15}$.

Regarding the risk factors, the findings of this study showed that $11(84.61)$ patients who had longer duration of catheterization ( $>7$ days) developed urinary tract infection out of 13 UTI patients. This findings was consistent with Islam 7 study who have reported that 13 (54.16\%) out of 24 post renal transplant patients had developed UTI who have more than 7 days catheterization. Schaeffer et $\mathrm{al}^{16}$ reported that, longer period of urethral catheterization may cause greater harm to the normal flora and may lead to a higher incidence of urinary infection. Rubin ${ }^{17}$ also showed, when the urethral catheters are removed within 1-4 days of the renal transplant, the development of infection is unusual.

It was observed from this observational study that, prolonged Foley's catheterization and post transplant hospitalization were found to be increased risk for leading to UTI. These finding also consistent with study by Iqbal et $\mathrm{al}^{5}$ in 2010 and Dantas et $\mathrm{al}^{18}$ in 2006 demonstrated that the length of hospitalization was related to the infection in post renal transplant patients.

From above discussion we can see that most of the patients suffered from UTI in early weeks after transplan- 
tation. There is slight increase in the rate of development of UTI in each day a bladder catheter is left in place, prolonged duration of dialysis, increased post transplant hospitalization. So early removal of urethral catheter and discharge of patients as early as possible is recommended.

\section{Conclusion:}

Most of post renal transplant recipients (61.90\%.) developed UTI in early post transplant periods. Enterococcus spp. (50\%) was the major pathogen causing UTI in transplant patients. Risk factors associated with UTI were prolonged urinary catheterization, prolonged period of dialysis and prolonged period of post transplant hospitalization.

\section{Acknowledgement:}

I would like to express my profound gratitude to honorable teacher Prof. Md. Rafiqul Alam, Professor \& Chairman, Department of Nephrology, and. A. H. Hamid Ahmed. Associate Professor, Department of Nephrology, Bangabandhu Sheikh Mujib Medical University, for their kind co-operation \& inspiration that helped me to make an avenue to work in the field of Nephrology related Microbiology.

\section{References:}

1. Dincken A, Tekin A, Turkyilmaz S. et al. Early and late urological complications corrected surgically following renal transplantation. Transplant Int. 2007; 20:702-7.

2. Pelle G, Vimont S, Levy PP, et al. Acute pyelonephritis represents a risk factor impairing long-term kidney graft function. Am J Transplant 2007; 7: 899 -907.

3. Alangaden GJ, Thyagarajan R, Gruber SA, et al. Infectious complications after kidney transplantation: current epidemiology and associated risk factors. Clin Transplant 2006;20: 401-409.

4. Sanchez RR, Ochoa DD, Paz RR. et al. Prospective study of urinary tract infection Surveillance after Kidney transplantation. BMC Infectious journal 2010; 10: 245-51.
5. Iqbal T, Nakvi R, Akter SF. Frequency of urinary tract infection in renal transplant recipients and effect on graft function. Journal of Pakistan Medical Association 2010; 60: 826-29.

6. Sousa SR, Galante NZ, Barbosa DA, OJ, PestanaI M. Incidence of infectious complications and their risk factors in the first year after renal transplantation. Journal Brasileiro de efrologia 2010; 32(1): $1-11$.

7. Islam MN. "Evaluation of infection in Renal transplant Recipient at earlier Post transplant Period (first three months)". Dhaka: BSMMU: 2005

8. Muñoz P. Management of Urinary Tract Infections and Lymphocele in Renal Transplant Recipients. Oxford Journals 2002; 33(1): 53-7.

9. Ram R, Murty KVD, Prasad N. Time table of infections after renal transplantation-South Indian experience. Indian J nephrol 2005; 15(2): $1-21$

10. Mathe Z, Treckmann JW, Heuer M et al, Stented Ureterovesica anastomosis in renal transplantation: does it influence the rate of urinary tract infections? Eur J Med Res 2010; 15(7):297-302.

11. De Souza RM, Olsburgh J. Urinary tract infection in the renal transplant patient. Nat Clin Pract Nephrol 2008; 4; 252-64.

12. Baron EJ, Thomson RB. Specimen collection, Transport, and processing: Bacteriology. In: Versalovic J, eds. Manual of clinical Microbiology.10th ed. USA, ASM Press, washington DC. $2011 ; 228-63$

13. Schieszer J, 2008. No, 1 Post- Transplant infection: UTIs. Renal \& Urology News, [Online] 11 November. Available at: < http:// www. Renal and urology news. Com/ issue/ november/ 01/ 2008/1413/> [ Accessed 26 October 2011].

14. Mahara B, Bonten H, Hooff HV, Fiolet H, Buiting AG, Stobberingh EE. Infectious Complications and antibiotic use in renal transplant recipients during a 1 - year follow up. Clin Microbial Infect 2001; 7: 619- 25.

15. Oliveira LC, Lucon AM, Nahas WC, Ianhez LE. Catheterassociated urinary infection in Kidney post- transplant patients. Sao Paulo Med. J. 2001; 119(5).

16. Schaeffer AJ, Chimiel J.Urethral meatal colonization in the pathogenesis of catheter associated bacteriuria. J Urol 1983; 130: 1096-9.

17. Rubin RH. Infection in the organ transplant recipient. In: Rubin RH, Young LS, editors. Clinical approach to infection in the compromised host. New York: Plenum medical, 1994; 629-705

18. Dantas SR, Kaboyama RH, Mazzali M, Moretti ML. Nosocomial infections in renal transplant patients: risk factors \& treatment implications associated with urinary tract and surgical site infections. J Hospital infect 2006; 63: 117-23. 